\title{
PARADOXOS E COMPLEXIDADE NA GESTÃO DO MOSAICO DE UNIDADES DE CONSERVAÇÃO DA ÁREA DE PROTEÇÃO AMBIENTAL CACHOEIRA DAS ANDORINHAS - OURO PRETO/MG
}

\author{
Raquel Faria Scalco* \\ Bernardo Machado Gontijo**
}

\section{RESUMO}

O objeto de estudo da presente pesquisa é o mosaico de unidades de conservação da Área de Proteção Ambiental Cachoeira das Andorinhas, localizado em de Ouro Preto-MG. O principal objetivo deste trabalho foi entender as relações sociais de produção e utilização dos recursos naturais e as contradições que dizem respeito à sua conservação. Para tanto, a metodologia adotada foi pesquisa qualitativa, com coleta de dados primários e secundários, com a utilização de diferentes procedimentos metodológicos: pesquisa bibliográfica; pesquisa de gabinete; trabalhos de campo; leitura e análise de atas de fóruns de participação; entrevistas semi-estruturadas com agentes envolvidos na gestão do mosaico da APA; e observação possibilitada pela participação em eventos locais. Os paradoxos e as contradições próprios da gestão de realidades complexas foram identificados, analisados, agrupados em temas e descritos por meio do que se convencionou chamar de fenômenos retro-interacionais. Assim, foi feita uma análise crítica e reflexiva sobre o mosaico da APA Cachoeira das Andorinhas, verificando a adequação de seus instrumentos de gestão e identificando as contradições e os paradoxos da gestão deste mosaico.

Palavras-chaves: Unidades de Conservação, Complexidade, Mosaico, APA Cachoeira das Andorinhas, Paradoxos.

\section{ABSTRACT}

The object of this research is the mosaic of protected areas from the Environmental Protection Area 'Cachoeira das Andorinhas', localized in Ouro Preto (MG). The main purpose of this research was to understand the social relations of production and utilization of natural resources and the contradictions related to its conservation. It was adopted the qualitativeanalysis as a strategy of research, with collection of primary and secondary data and with the utilization of different methodological proceedings: bibliographic research, cabinet research, field works, analysis of the proceedings from the forums, semi-structured interviews with agents that are involved in the management of the mosaic and observations enabled by the participation in local events. The paradoxes and contradictions intrinsic on the management of complexes realities were identified, analyzed, arranged in themes and described through what was called retro-interactional phenomenons. Therefore, it was made a critical and reflexive analysis about the mosaic from the Environmental Protection Area 'Cachoeira das Andorinhas', verifying the suitability of its instruments of management and identifying the contradictions and paradoxes from the anagement of this mosaic.

Key-words: Protected Areas, Complexity, Mosaic, Environmental Protection Area 'Cachoeira das Andorinhas', Paradoxes.

*Professora do Departamento de Turismo da Universidade Federal dos Vales do Jequitinhonha e Mucuri. email: raquel.scalco@yahoo.com.br

** Professor do Departamento de Geografia da Universidade Federal de Minas Gerais. email: gontijobm@yahoo.com.br 
Paradoxos e complexidade na gestão do mosaico de unidades de conservação da área de proteção ambiental cachoeira das andorinhas - ouro preto/mg. pp. 90 - 106.

\section{INTRODUÇÃO}

A Área de Proteção Ambiental Estadual Cachoeira das Andorinhas está localizada em Ouro Preto-MG, distante aproximadamente $100 \mathrm{~km}$ da capital Belo Horizonte, tendo sido criada em 1989, por meio do Decreto Estadual n³0.264.

Vale ressaltar que a APA está inserida em um mosaico maior formado pela Reserva da Biosfera da Serra do Espinhaço, que é uma forma de gestão integrada e participativa dos recursos naturais, visando o desenvolvimento sustentável e a melhoria da qualidade de vida na região por ela abrangida. São, ainda, objetivos do programa: a proteção da biodiversidade, o desenvolvimento de pesquisas, o monitoramento ambiental e a educação ambiental. (IEF/SAT, 2005)

A Reserva da Biosfera da Serra do Espinhaço tem suas áreas núcleos - de maior restrição de atividades - constituídas pelas UCs de proteção integral. Já as zonas de amortecimento da Reserva da Biosfera são formadas por um raio de dez quilômetros no entorno destas UCs, acrescido das unidades de conservação de uso sustentável da região (IEF/SAT, 2005, p. 12). Assim, a Reserva da Biosfera da Serra do Espinhaço pode ser considerada um grande mosaico de unidades de conservação, sendo previsto, pela Lei do SNUC, a gestão integrada deste território.

Pode-se considerar ainda um outro mosaico do qual a APA faz parte, abrangendo desde a Região Metropolitana de Belo Horizonte até o Maciço do Caraça. Desta forma, as inúmeras UCs presentes nesta região também devem ser geridas de forma integrada, garantindo, assim, maiores possibilidades de conservação ambiental.

Vale destacar, por fim, que no próprio município de Ouro Preto está localizado um outro mosaico de unidades de conservação, de diversas categorias de manejo, e que, também, devem ser consideradas em seu conjunto. Este mosaico abrange a APA Cachoeira das Andorinhas com as UCs presentes em seu interior, a Estação Ecológica do Tripuí, o Parque Estadual do Itacolomi, o Horto Botânico, o Vale dos Contos e o Monumento Natural Municipal Nossa Senhora da Lapa.
A APA Cachoeira das Andorinhas, objeto de estudo da presente pesquisa, também é um outro mosaico. Em seu interior existem outras três áreas protegidas que formam este mosaico: a Floresta Estadual do Uaimii, o Parque Natural Municipal Cachoeira das Andorinhas e a Fazenda da Brígida (área protegida mantida pela Universidade Federal de Ouro Preto - UFOP), como pode ser observado pelo mapa da fig. 1.

Mosaico das Unidades de Conservação no interior da APA Cachoeira das Andorinhas - Ouro Preto - MG

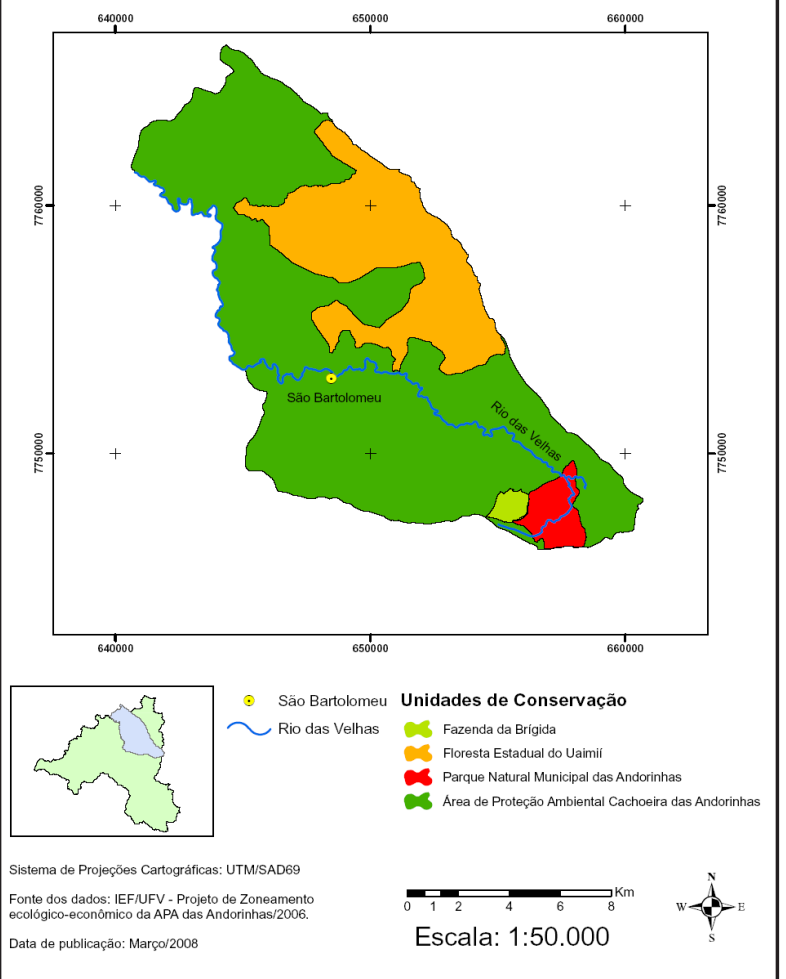

Figura 1 - Mapa do mosaico de UCs da APA Cachoeira das Andorinhas -Fonte - IEF/UFV, 2006.

A criação dessas UCs se devem à necessidade de proteger as cabeceiras de um dos rios mais importantes de Minas Gerais, o Rio das Velhas, que tem sua nascente principal próximo à Cachoeira das Andorinhas, no interior da APA. 
Além disso, as águas desse rio contribuem para a captação de água do sistema de abastecimento da Região Metropolitana de Belo Horizonte.

\section{Como característica geográfica} relevante, vale ressaltar o relevo bastante acidentado da região, destacando a Serra Geral, na parte leste da APA e a Serra de Ouro Preto, em sua parte sul. Vale, ainda, explicitar que a vegetação predominante é a Mata Atlântica. Estas características ressaltam a importância e fragilidade ambiental da área, bem como a necessidade de criação de mecanismos de proteção desse rico patrimônio.

O principal objetivo deste trabalho foi entender as relações sociais de produção e utilização dos recursos naturais e as contradições que dizem respeito à sua conservação. Além disso, pretendeu-se pesquisar as implicações da criação e gestão do mosaico de UCs no modo de vida das comunidades que moram em seu interior.

Este mosaico foi analisado, nesta pesquisa, como um sistema complexo e multidimensional, não sendo possível uma análise fragmenta desta realidade. Isso implica na análise de um conjunto de inúmeras variáveis interrelacionadas que perpassam o objeto de estudo que está inserido em um contexto complexo, dinâmico e sempre articulado. Como bem coloca Leff:

A complexidade ambiental marca o limite do pensamento unidimensional, da razão objetivante e coisificante. A epistemologia ambiental lança-se assim à aventura do pensamento da complexidade, como uma visão sobre as relações de processos que supera um conhecimento orientado a estabelecer o vínculo entre o conceito e o real (entre coisas, fatos, dados, variáveis e fatores), que é acessado pela separação entre sujeito e objeto do conhecimento. (LEFF, 2004, p. 29)

Destaca-se que a criação dessas UCs bem como outras leis ambientais incidentes na área, são importantes para a conservação dos recursos naturais, porém, coíbem a realização de diversas atividades tradicionalmente desenvolvidas pela comunidade. Torna-se, portanto, fundamental que o processo de gestão das UCs considere a indissociabilidade entre natureza e sociedade, na tentativa de conservar os recursos naturais existentes, compatibilizando tais processos com as demandas da sociedade.

\section{MATERIAIS E MÉTODOS}

A metodologia adotada nesse trabalho foi a pesquisa qualitativa, com coleta de dados primários e secundários, com a utilização de diferentes procedimentos metodológicos.

Primeiramente, foi feita uma pesquisa bibliográfica sobre unidades de conservação, legislação ambiental, participação comunitária e complexidade. Vale destacar, também, que toda análise aqui realizada baseou-se na legislação ambiental em vigor.

Posteriormente, foi realizada pesquisa de gabinete nos principais órgãos e instituições ligados à gestão das UCs. Nesta etapa foi possível ter acesso a alguns estudos sobre a área que subsidiaram esta pesquisa.

Além disso, foram realizados diversos trabalhos de campo para levantamento de dados sobre o local. Estes trabalhos de campo foram realizados no período de janeiro a setembro de 2008.

Foi feita, ainda, leitura e análise de atas dos fóruns de participação que se mostraram relevantes neste trabalho, quais sejam: Comitê de Bacia Hidrográfica do Rio das Velhas, CODEMAOP e Conselho Consultivo da APA Cachoeira das Andorinhas. Essa etapa metodológica se mostrou relevante como forma de identificar as principais tensões, conflitos, problemas e/ou paradoxos da gestão desse mosaico, possibilitando, também, a identificação dos agentes envolvidos com essas questões. Dessa forma, esta etapa tornou-se necessária como forma de subsidiar a elaboração do roteiro de entrevistas e seleção dos agentes a serem entrevistados.

Finalmente, foram feitas entrevistas 
Paradoxos e complexidade na gestão do mosaico de unidades de conservação da área de proteção ambiental cachoeira das andorinhas - ouro preto/mg. pp. 90 - 106.

semi-estruturadas com 29 agentes envolvidos na gestão do mosaico da APA. Estas entrevistas foram realizadas entre junho e setembro de 2008 e, posteriormente, foram transcritas e analisadas.

Estas etapas metodológicas permitiram identificar e analisar alguns paradoxos e contradições na gestão deste mosaico, de forma a ressaltar a complexidade implícita na gestão de UCs, principalmente no que se refere à relação entre necessidade de conservação dos recursos naturais e as demandas das comunidades locais.

Os paradoxos e as contradições próprios da gestão de realidades complexas foram identificados, analisados, agrupados em temas e descritos por meio do que se convencionou chamar fenômenos retro-interacionais.

\section{RESULTADOS E DISCUSSÕES}

As etapas metodológicas acima descritas permitiram perceber a complexidade da gestão das UCs envolvidas neste estudo, ressaltando a importância da análise multidimensional das temáticas apresentadas, bem como possibilitando a compreensão dos paradoxos e das contradições existentes neste processo.

A realidade aqui analisada será apresentada considerando-se os diversos paradoxos identificados no âmbito desta pesquisa. Estes foram agrupados em temas e descritos por meio dos fenômenos retro-interacionais. Esses fenômenos são assim denominados por estarem intrinsecamente relacionados, em constante interação e retro-alimentação, não sendo possível o seu entendimento de forma fragmentada, isolada de seu contexto mais amplo.

Assim, cada um dos fenômenos retro-interacionais aqui apresentados deve ser entendido como uma das dimensões da mesma realidade complexa, que tem como pano de fundo, dois outros fenômenos mais abrangentes e que ultrapassam o âmbito dessa pesquisa, quais sejam: a criação de unidades de conservação como forma de proteger a natureza da destruição causada pelo próprio homem; e a necessidade de sobrevivência das comunidades locais que possuem estilos de vida de grande dependência em relação aos recursos naturais.

O termo fenômenos retro-interacionais baseou-se em Morin (1990), que discorre sobre as inúmeras inter-retroacções do desafio da complexidade; e em Gontijo (2003), que descreve os fenômenos interacionais do turismo no povoado de Lapinha-MG.

Na fig.2, apresenta-se um esboço dos fenômenos retro-interacionais que refletem os paradoxos e as contradições da gestão do mosaico de UCs da APA Cachoeira das Andorinhas. Em seguida, cada um desses fenômenos será explicado e analisado.

A APA Estadual Cachoeira das Andorinhas foi criada em 1989 pelo Decreto Estadual $n^{\circ} 30.264$, de 16 de outubro de 1989, com alteração de dispositivos pelo Decreto Estadual $n^{\circ} 42.912$, de 26 de setembro de 2002 e possui uma área total de 18.700 hectares. Seu processo de criação não foi acompanhado de participação e/ ou debate com a comunidade, como afirma o gerente da APA: "Foi uma decisão como era comum na época, uma decisão de governo. Não houve nenhum debate interno, nenhuma discussão que envolvesse a comunidade. (Funcionário IEF, entrevista realizada em 12/08/08).

A criação da APA ocorreu devido à necessidade de preservar as nascentes do Rio das Velhas, as quais contribuem para a captação de água do sistema de abastecimento da Região Metropolitana de Belo Horizonte. Além disso, a região constitui patrimonio natural de reconhecido valor histórico, cultural e turístico.

De acordo com o SNUC uma APA é considerada uma categoria de UC pertencente ao grupo de unidades de conservação de uso sustentável dos recursos e possui a seguinte definição:

Uma área geral extensa, com um certo grau de ocupação humana, dotada de atributos abióticocs, bióticos, estéticos ou culturais, especialmente importantes para a qualidade de vida e o 
bem estar da população humana e tem como objetivos básicos proteger a diversidade biológica, disciplinar o processo de ocupação e assegurar a sustentabilidade do uso dos recursos naturais. (Lei 9.985, art. 15, 2000)

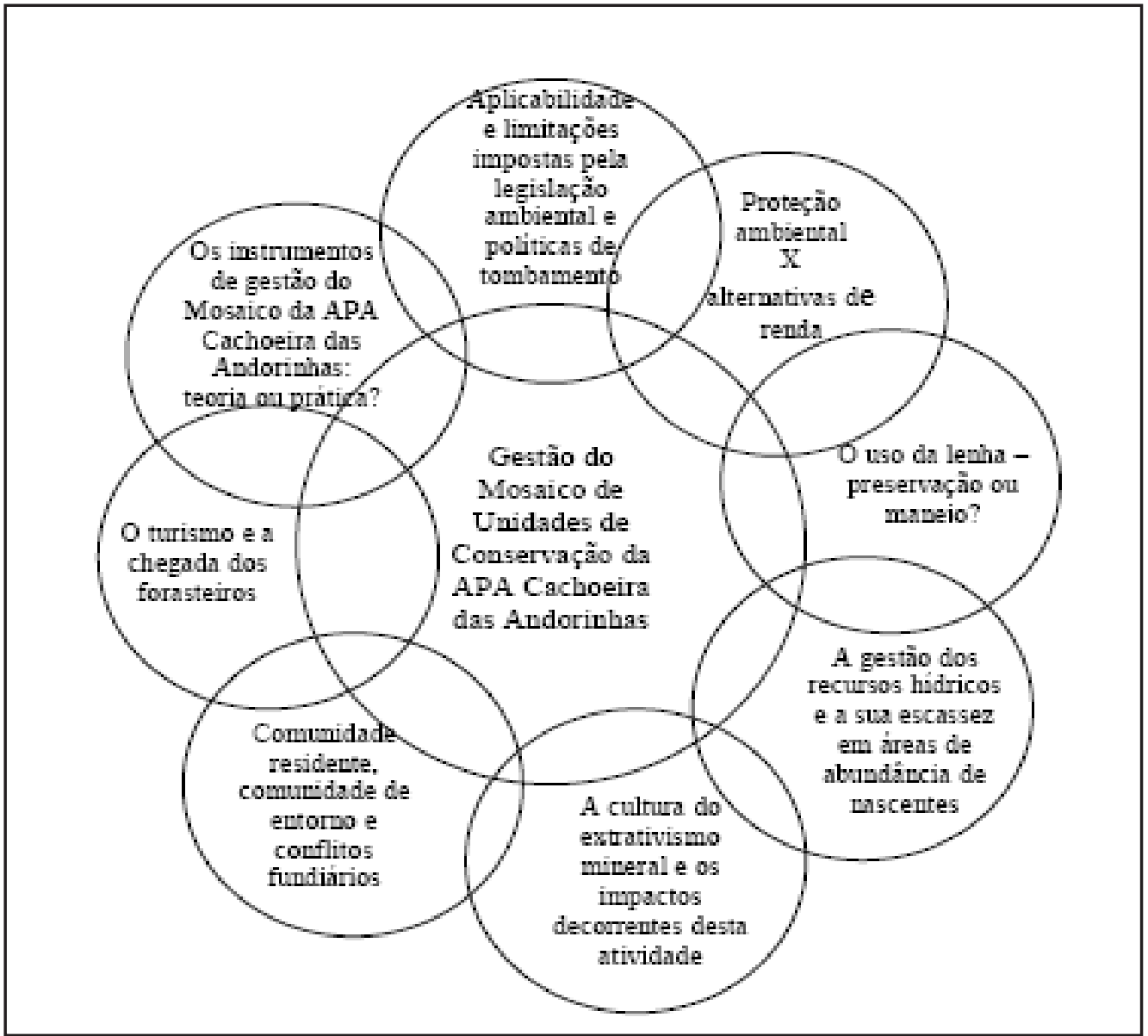

Figura 2 - Fenômenos retro-interacionais da gestão do Mosaico de UCs da APA Cachoeira das Andorinhas. Fonte: o autor, 2008

Como pode ser percebido, a criação desse tipo de unidade de conservação se deve mais à necessidade de disciplinar o crescimento urbano desordenado, sem desapropriação das comunidades locais e garantindo o desenvolvimento de atividades necessárias às dinâmicas sociais. Desta maneira, as APAs representam uma inovação no sistema de gestão de unidades de conservação no Brasil, uma vez que permitem a permanência de comunidades locais no seu interior, de forma a garantir a sua qualidade de vida, mas também protegendo os recursos naturais existentes no local.

A Floresta Estadual do Uaimii abrange uma área de aproximadamente 4.398 hectares, abrigando uma expressiva área de mata nativa, onde se encontra grande parte das nascentes dos 
Paradoxos e complexidade na gestão do mosaico de unidades de conservação da área de proteção ambiental cachoeira das andorinhas - ouro preto/mg. pp. 90 - 106.

tributários da margem direita do Rio das Velhas.

A Floresta foi criada em 2003, pelo Decreto Estadual sem número, de 21 de outubro de 2003, com o objetivo de desenvolver atividades voltadas à pesquisa e exploração sustentável da candeia, ao uso turístico e recreativo, à educação ambiental e à proteção de mananciais para o abastecimento público.

Esta categoria de UC foi definida pelo SNUC também como Unidades de Conservação de uso sustentável com as seguintes características:

Uma área com cobertura vegetal florestal de espécies predominantemente nativas e tem como objetivo básico o uso múltiplo sustentável dos recursos florestais e a pesquisa científica, com ênfase em métodos para a exploração sustentável de florestas nativas. (Lei 9.985, art. 170, 2000).

Esse tipo de unidade de conservação tem como objetivo principal a produção econômica sustentável de madeira e outros produtos vegetais; a proteção de recursos hídricos; a pesquisa científica, o manejo da fauna silvestre e a recreação em contato com a natureza.

O uso sustentável de parte de seus recursos florestais é permitido e incentivado, desde que sejam respeitados os mecanismos de sustentação dos ecossistemas, baseando-se no seu uso múltiplo e no manejo dos recursos naturais. As Florestas são importantes, também, por contribuírem para a manutenção da biodiversidade, para a recuperação das áreas degradadas e para o desenvolvimento de projetos de educação ambiental. São, ainda, importantes para proteger os recursos genéticos e desenvolver técnicas de produção e/ou aproveitamento racionais dos recursos florestais. Assim, essas unidades de conservação devem ser manejadas de forma a cumprir finalidades econômicas, de pesquisa científica, lazer e recreação, turismo e conservação dos recursos naturais.

Deve-se ressaltar, também, que essa categoria de unidade de conservação ainda é muito recente em Minas Gerais, e os órgãos gestores têm muita dificuldade no estabelecimento do manejo florestal, o que acaba por dificultar sua implantação e gerenciamento de acordo com os objetivos da categoria.

Já o Parque Municipal da Cachoeira das Andorinhas foi criado em 30 de dezembro de 1968, pela Lei Municipal no 305/68, que definia sua área por um raio de um quilômetro, tendo como centro a Cachoeira das Andorinhas. Em 2005, a Câmara Municipal aprovou o projeto de lei que disciplina sobre tal assunto e o Prefeito, então, sancionou a Lei no 69/05, estabelecendo novos limites para a área do Parque, abrangendo uma área total de 557 hectares.

O relevo da área onde está localizado o Parque Natural Municipal Cachoeira das Andorinhas é bastante acidentado, com afloramentos de quartzitos e arenitos. A vegetação dominante pode ser caracterizada como pertencente ao bioma Mata Atlântica, no fundo dos vales, tendo sua composição alterada na medida em que há um aumento da altitude, com predomínio da candeia, até ceder lugar aos campos de altitude, nas partes mais elevadas

À época da pesquisa, o Parque estava em obras para a construção de infra-estrutura para recebimento de visitantes. Estas obras foram realizadas com recursos de compensação ambiental da empresa de mineração Samarco, que atua no entorno da APA.

A Lei do SNUC define esta categoria como uma unidade de conservação de proteção integral que tem como objetivo básico:

[...] a preservação de ecossistemas naturais de grande relevância ecológica e beleza cênica, possibilitando a realização de pesquisas científicas e o desenvolvimento de atividades de educação e interpretação ambiental, de recreação em contato com a natureza e de turismo ecológico. (Lei 9.985, art. $\left.11^{\circ}, 2000\right)$.

Essa categoria de unidade de conservação foi a primeira a ser criada no Brasil, em 1937, com a implantação do Parque Nacional do Itatiaia, na divisa dos estados do Rio de Janeiro, Minas Gerais e São Paulo. (CAMARGOS, 1999).

A forma como os parques nacionais são instituídos, no Brasil, segue o modelo norte- 
americano, que prevê a separação entre sociedade e natureza, não admitindo a presença humana no interior das unidades de conservação. Essa é a principal crítica feita a essa categoria de manejo, pois exclui as populações locais, gerando muitos conflitos socioambientais. De acordo com Diegues:

[...] já é sabido que as comunidades locais a serem afetadas pela criação de unidades de conservação devem ser tratadas como aliadas e não adversárias da conservação, e que seu alijamento do processo decisório pode transformá-las, no final, em sérias adversárias de uma preservação da natureza malconcebida e maldesenvolvida. (DIEGUES, 2000, p.119).

Porém, há que se ressaltar, também, a sua importância no que se refere à preservação da biodiversidade. Por ser uma categoria bastante restritiva, os parques têm importe papel na proteção de ecossistemas de grande relevância ambiental e que apresentam maior fragilidade frente aos possíveis impactos antrópicos.

Já a Fazenda da Brígida, apesar de não ser uma unidade de conservação nos moldes do SNUC, ela pode ser considerada uma área protegida, uma vez que a Universidade Federal de Ouro Preto mantém a área e trabalha para minimizar a alteração do uso do solo em seu interior. A área da Fazenda possui 248 hectares (UFOP, 2001).

Considerando os conceitos e as atribuições das UCs propostos pelo SNUC (já tratados acima), percebe-se que a criação da APA e das demais UCs em seu interior tiveram como objetivo garantir a conservação dos recursos naturais, aliada a melhoria das condições de vida da população residente em seu interior e entorno. Porém, a criação dessas UCs, associada a outras leis ambientais e políticas de tombamento, trouxeram diversas restrições no desenvolvimento de atividades que garantiam a geração de renda pela comunidade.
É preciso lembrar que as atividades econômicas historicamente desenvolvidas na área são incompatíveis com os objetivos de criação das UCs e por isso, muitas delas foram proibidas em função de terem como base a extração dos recursos naturais. As principais atividades econômicas da área, antes da criação das UCs, eram: produção e venda de carvão vegetal feito com mata nativa; corte e venda de lenha para uso no fogão à lenha; e extração mineral (primeiramente ouro e depois bauxita e quartzito).

Com a criação das UCs e as restrições impostas por outras leis ambientais, principalmente pela Lei da Mata Atlântica, todas estas atividades foram proibidas, tornando-se restritas as possibilidades de geração de renda pela comunidade. Isso tem contribuído muito com o constante aumento do êxodo rural na região.

Torres (1999), para enfatizar o grande êxodo rural pelo qual passou o distrito, apresentou em seu estudo um levantamento realizado pelos próprios moradores do local. Segundo eles, na época do estudo existiam no distrito cerca de setenta e seis casas totalmente vazias, oito casas com apenas um morador e treze casas com dois moradores. A opinião de um Doceiro do local enfatiza esta questão: "O principal problema aqui é o êxodo rural. Você fica aqui dia de semana, você vê as casas tudo fechada. Tá ficando aqui é só os mais velhos. Porque aqui não roda dinheiro." (Doceiro, entrevista realizada em 22/07/08).

De acordo com as análises de Machado, a população do distrito vem diminuindo desde a década de 1950, tendência essa mantida até a década de 2000, inclusive associada a uma maior restrição do uso do solo e do desenvolvimento de algumas atividades econômicas, em função da criação da APA, em 1989, e do decreto proibindo o corte raso da vegetação de Mata Atlântica, aprovado em 1993. (vide Fig. 3) 


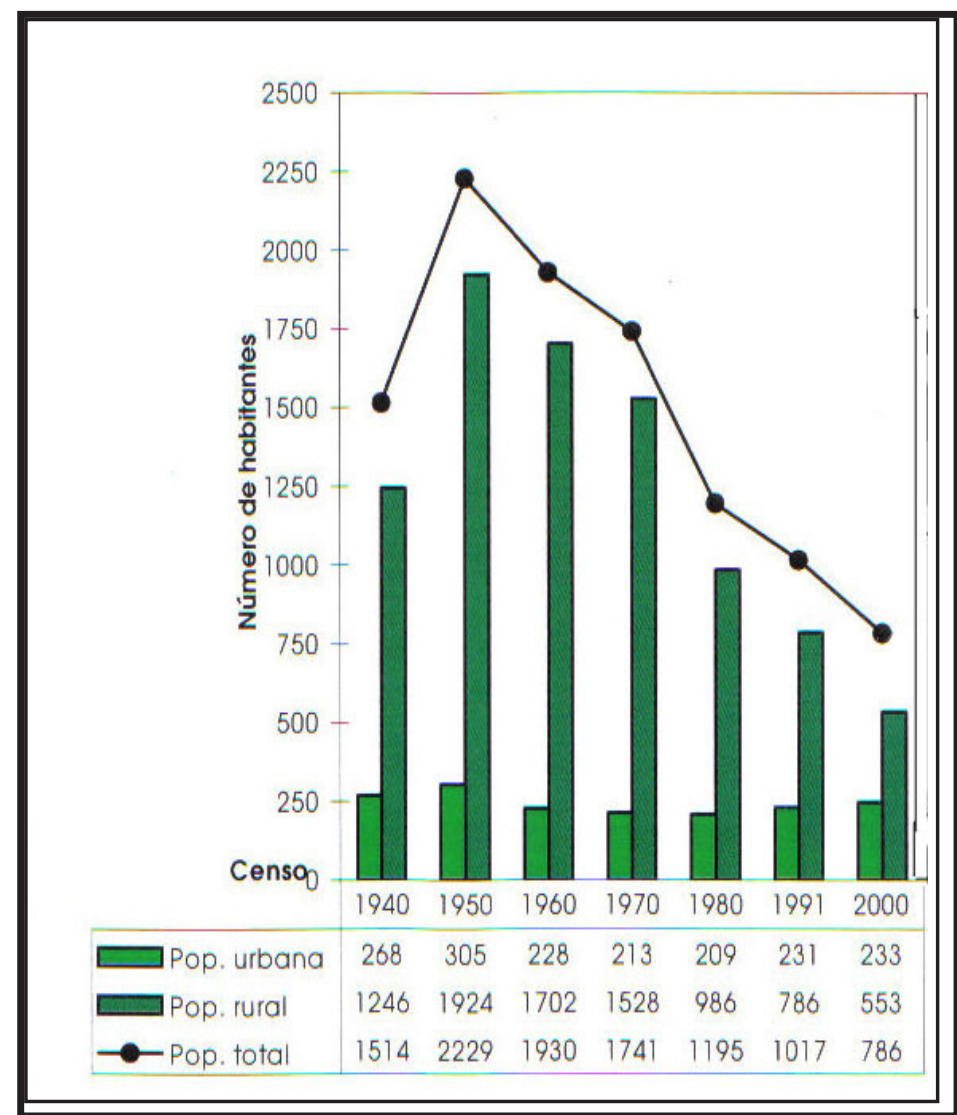

Figura 3 - População do distrito de São Bartolomeu - 1940 a 2000 .Fonte: Gráfico adaptado de Machado, 2001, p. 35.

Atualmente, a produção artesanal de doces reconhecida, em 2008, como Patrimônio Imaterial do Município de Ouro Preto, é a principal atividade econômica da APA. Porém, é importante frisar que os doceiros têm encontrado muita dificuldade em conseguir lenha para produzi-lo, em função das restrições impostas pela Legislação Ambiental. Vale destacar que, de acordo com as tradições e com o próprio registro de seu processo de fabricação, o doce deve ser feito no fogão à lenha. Esse interessante paradoxo pode ser percebido pelo depoimento de um doceiro: "Eles proibiram a gente de cortar lenha e nós ficamos roubando. Nós temos que roubar lenha no terreno nosso. É um absurdo porque o terreno é nosso, a gente paga imposto, né? Tudo direitinho." (Doceiro, entrevista realizada em 15/07/08).

Apesar do cerceamento, que recai principalmente sobre a comunidade, pôde-se perceber que tanto a criação de UCs de uso sustentável, como a aplicação das leis ambientais têm encontrado dificuldades para alcançar seus objetivos no que diz respeito a garantir a qualidade de vida e a sustentabilidade no uso dos recursos naturais da área. Assim, apesar da comunidade se sentir impedida de desenvolver uma série de atividades que tradicionalmente desenvolvia, vários processos degradadores 
continuam ocorrendo, como por exemplo, o roubo de candeia, desmatamento das margens dos rios e o lançamento de esgoto in natura nos cursos d'água da região.

Além disso, vale ressaltar que, tanto as leis ambientais quanto as políticas de tombamento, atuam mais no sentido de coibir o desenvolvimento de atividades e práticas tradicionais da comunidade, do que no sentido de conscientizar, de educar, de trazer novas possibilidades de renda e de desenvolvimento, por meio de incentivos para a conservação e recuperação do patrimônio natural e cultural da APA Cachoeira das Andorinhas. O depoimento de um morador do local e produtor de doce corrobora com esta afirmação: "As pessoas daqui são muito resistentes. A visão tanto de patrimônio, como de IEF, ainda é aquela visão negativa, que só impede e nada faz." (Doceiro, entrevista realizada em 22/07/08).

Destaca-se que o entorno de Ouro Preto, de uma forma geral, e a região da APA Cachoeira das Andorinhas, mais especificamente, sempre sofreram com os impactos advindos da extração de produtos vegetais. Certamente, a questão que envolve a extração e uso da lenha é a principal causa de conflito entre o poder público e a comunidade local. De um lado, há as restrições impostas pela legislação ambiental, principalmente a Lei da Mata Atlântica, juntamente com a criação das UCs, e, de outro, as demandas da comunidade por lenha, seja para consumo próprio, seja como fonte complementar da renda.

O discurso do IEF é de que o proprietário pode retirar lenha seca do próprio terreno, sendo que, por lei, é permitido retirar 28 estéreos $^{1}$ por ano, mediante autorização. Além disso, de acordo com os funcionários do órgão, na Floresta do Uaimii é proibido retirar madeira, sendo que o local será mais utilizado para estudos, pesquisas e desenvolvimento de novas tecnologias sobre manejo florestal. Desta forma, eles transferem o problema para os proprietários rurais que têm área de mata, fora da Floresta, para que eles manejem e comercializem a lenha.

O IEF afirma também que, no futuro, haverá estudo para resolver este problema e que o plano de manejo é que vai definir o que poderá ou não ser feito dentro da Floresta e em seu entorno. Porém, há um descompasso no que se refere às demandas da comunidade e às soluções previstas pelo Estado. A proposta do poder público prevê soluções a longo prazo e a comunidade precisa da lenha para satisfazer suas necessidades diárias. Isso pode ser percebido no discurso de um funcionário do IEF:

A gente tem que estudar, para ver o que eu posso fazer, sem afetar a Floresta. A idéia do manejo da candeia pra fazer mourão também requer estudo. Eu tenho que saber o quanto e o como eu vou tirar de candeia. Tem também a idéia de extração do óleo, de fazer uma fábrica. Então, tudo isso é a longo prazo. Não é nem pra esse ano e nem pro ano que vem. É tudo a longo prazo. São só propostas. (Funcionário do IEF, reunião do DIPUC, 26/08/08).

Em relação à permissão de retirada de 28 estéreos por ano, é preciso ressaltar que a autorização para o corte dessa quantidade de lenha só pode ser feita mediante autorização do órgão, que requer a apresentação de toda a documentação do proprietário e da propriedade. Isso se torna um problema porque grande parte dos proprietários não possui registro de suas terras.

Destaca-se, também, que a Lei da Mata Atlântica, Lei no 11. 428/2006, prevê que pode ser retirada parte da vegetação em área de Mata Atlântica em estado de regeneração para o desenvolvimento de atividades de interesse social, dentre elas "as atividades de manejo agroflorestal sustentável praticadas na pequena propriedade ou posse rural familiar que não descaracterizem a cobertura vegetal e não prejudiquem a função ambiental da área" (Lei 11.428, art. 1², 2006). Esta lei prevê, ainda, "a exploração eventual, sem propósito comercial direto ou indireto, de espécies da flora nativa, para consumo nas propriedades ou posses das populações tradicionais ou de pequenos produtores rurais, independe de autorização dos órgãos competentes, conforme regulamento" (Lei 11.428 , art. $\left.9^{\circ}, 2006\right)$.

Porém, o que acontece, na prática, é que, mesmo tendo uma legislação que permite retirar 
Paradoxos e complexidade na gestão do mosaico de unidades de conservação da área de proteção ambiental cachoeira das andorinhas - ouro preto/mg. pp. 90 - 106.

certa quantidade de madeira das propriedades, as pessoas não estão conseguindo fazê-lo e, se o IEF pegar alguém transportando madeira, mesmo que para consumo próprio, a pessoa é autuada, multada e a madeira é apreendida. Um funcionário do IEF, com muita sobriedade, tenta explicar esses discursos desencontrados.

Até uma certa quantidade de metros por ano de lenha você pode usar para a sua subsistência, mas a lei não enxerga isso, não separa isso. Então como que funciona? Se você for autuado, você vai recorrer e alegar isso. O que você não pode fazer é supressão de vegetação, é a Lei da Mata Atlântica. Eu posso fazer o manejo, posso até cortar um pouco da mata, para a minha subsistência. Eu não posso comercializar. Só que a lei não consegue diferenciar. Se tiver uma fiscalização e te pegar transportando essa lenha, pressupõe que você está comercializando, e então você vai ser autuado, mas cabe recurso. Se você comprovar que é para a sua subsistência, não tem problema. Só que não existe uma maneira mais simplificada de autorizar isso. A autorização é muito burocrática. Como nenhum técnico quer se expor por facilitar o processo, o mais fácil é proibir tudo. (Funcionário do IEF, entrevista realizada em 12/08/08).

Percebe-se, então, que a comunidade, por não ter opção, acaba entrando na ilegalidade. E isso acontece muito em função da lentidão do serviço público ou da não priorização de ações e/ ou políticas públicas para solucionar esse problema. Enquanto essas soluções não chegam, as pessoas continuam retirando a lenha, porque necessitam dela, mas à mercê de serem autuadas e multadas, como se estivessem cometendo um crime. É preciso, então, criar alternativas para a população local e promover ações que compatibilizem a conservação ambiental com o atendimento às demandas locais.

Outro problema comum na área da APA diz respeito à qualidade e disponibilidade de recursos hídricos. A APA Cachoeira das Andorinhas e as demais UCs desse mosaico foram criadas tendo a questão das águas como principal motivador. Porém, percebe-se que, mesmo com a criação das UCs, os recursos hídricos continuam sendo ameaçados por diversos fatores que comprometem a qualidade de suas águas e a disponibilidade desse recurso.

O problema que mais contribui para a degradação do Rio das Velhas, desde as suas nascentes no Morro de São Sebastião, é o lançamento de esgoto. O assoreamento também é um grande problema, causado principalmente pelo histórico da região que sempre esteve ligado ao desenvolvimento de atividades minerarias.

Vale destacar, ainda, o problema da escassez de água para abastecimento em alguns bairros e povoados no interior da APA, como pode ser observado pelo depoimento abaixo:

O principal problema aqui é a água. A quantidade e a qualidade. Hoje mesmo a gente tá sem uma gota de água aqui. Porque a água que cai aqui é um pouquinho só. A gente tá correndo atrás para ver se a gente arruma um lugar para pegar a água para a comunidade, porque não tem. Aqui tem muita nascente, mas muitas vezes está dentro de terrenos de particulares. Eu não sei bem, mas pelo que eu sei, se você tem água dentro do seu terreno, você não é dono, mas também não tem como outra pessoa ir lá e pegar. A gente precisa do apoio da SEMAE para estar arrumando isso. (Representante de Associação Comunitária, entrevista realizada em 13/08/08).

Destaca-se que a APA abrange uma área rica em nascentes e cursos d'água, o que faz com que fique claro que o problema não é a falta de recursos hídricos e sim o seu gerenciamento inadequado.

Em função de suas características geológicas, a região da APA sofreu e ainda sofre com outro processo de degradação, causado pela mineração. Primeiramente a mineração do ouro, ainda no século XVII, deixou marcas que podem ser vistas ainda hoje. Os terraços fluviais do Rio das Velhas foram bastante remexidos, a mata ciliar foi substituída por charnecas esburacadas e o leito do Rio vem sendo progressivamente assoreado.

Com a decadência do ouro, a região passou por um momento de estagnação econômica, mas no início do século XIX, começou a ser praticada outra forma de exploração: a mineração 
e fundição de ferro. No entorno da APA ainda estão ativas três grandes minas de extração de minério de ferro.

Existem, também, no interior da APA, áreas já bastante degradadas em função de dois processos de mineração, nas áreas circunvizinhas ao Parque Cachoeira das Andorinhas. O primeiro processo é relativo à extração de bauxita pela empresa Novelis, desde a década de 1960. O segundo, diz respeito à extração de quartzito nos limites do Parque, ocorrendo há mais de cinqüenta anos.

Mesmo a maioria desses processos não estando mais em curso, os impactos ambientais decorrentes de tal atividade são grandes, principalmente no que se refere ao assoreamento do Rio das Velhas e diminuição de sua vazão.

A região de Ouro Preto tem outra especificidade, que se refere à questão de registro e posse de terrenos. Desde a época do descobrimento e exploração do ouro e da fundação de Vila Rica, que os terrenos foram sempre distribuídos por influência política e/ou religiosa, sendo que o registro dos imóveis na região nunca foi uma coisa muito comum (Delamare, 1935). Assim, todo o processo de criação e implantação das UCs desse mosaico acaba esbarrando na questão do registro de terrenos, seja referente à necessidade de desapropriação de terras, seja em função da necessidade de documentação para o desenvolvimento de atividades econômicas ou de projetos de uso sustentável dos recursos naturais.

Tanto o Parque das Andorinhas quanto a Floresta do Uaimii possuem problemas fundiários, e muitos desses processos referem-se a proprietários que não possuem documentação de seus terrenos, dificultando a desapropriação e conseqüente indenização de suas terras (IBAMA, 2000; IBAMA, 2002; PMOP, 2006). A Floresta do Uaimii enfrenta ainda um outro problema, que diz respeito a um novo formato previsto para a UC, que fecharia um enclave de propriedades particulares no interior da unidade, como pode ser percebido pelo depoimento abaixo.

Tem uma dificuldade aqui que é o formato da unidade de conservação, que tem vários formatos. Mas qual é a área da Floresta? Ainda não tá fechado, mas o decreto prevê este formato (formato que consta nos mapas aqui apresentados). Eu posso aumentar a área da Floresta, mas não posso diminuir. A gente tem área aqui, na Fazenda da Ajuda, que são de propriedade dos Necas. Essa área está dentro da Floresta, eu não tenho jeito de tirar ela. Então, quando resolver a questão fundiária, os processos que estão na justiça por usucapião, estas coisas, o IEF vai indenizar e vai comprar essa área. Mas essa indenização pode ser daqui a dois anos, como pode ser daqui a dez anos, como pode ser daqui a vinte anos. Como tá tendo estes problemas fundiários, a proposta da VDL é passar uma parte da Fazenda Conta História para a gente, para completar os 4.398 hectares previstos no decreto. Daí vem aquele outro desenho que vocês viram, que é fechando isso aqui (a península de propriedades). Isso significa que a área da Floresta vai aumentar. (Funcionário do IEF, reunião do DIPUC, 26/08/08).

Alguns moradores desse local já estão preocupados com o futuro, uma vez que o fechamento do enclave pode ser o início de um processo sem volta de transformação das propriedades de entorno em propriedades do interior da Floresta e, assim, passíveis de desapropriação. Como solução, estão sendo criadas RPPNs (Reserva Particular do Patrimônio Natural) no local como forma de garantir a dominialidade das terras.

Eu acho que se eu não tomar medidas de proteção da minha área, eu acho que, no futuro, essas áreas aqui são muito favoráveis a uma desapropriação. Qual é a estratégia que nós vamos desenvolver para isso? É transformar parte da minha propriedade em RPPN. Com isso, eu faço um anel de proteção na minha área, porque o meu interesse não é de produção mesmo, é ter uma área preservada, mas assim, pelo menos, eu garanto a dominialidade. Porque você vai fazer um outro decreto em cima de uma área que já foi decretada de proteção? Isso não cabe. (Proprietário de terra na península, entrevista realizada em 12/08/08).

Um outro fenômeno que se percebe na área da APA é o crescimento das atividades 
Paradoxos e complexidade na gestão do mosaico de unidades de conservação da área de proteção ambiental cachoeira das andorinhas - ouro preto/mg. pp. $90-106$.

relacionadas ao turismo. Com todas as restrições de uso dos recursos naturais impostas sobre a população residente na APA e, em função das características históricas, culturais e ecológicas da área, o turismo tem se sobressaído nesse cenário como uma possível solução para a falta de emprego e renda para a população local. A chegada dos forasteiros também é um fenômeno muito comum e muitos deles estão sendo atraídos pela possibilidade de criação de empreendimentos turísticos no local. Esses dois fatores podem confluir para um desenvolvimento harmonioso do turismo, com o envolvimento da comunidade, gerando renda e viabilizando a permanência das pessoas em seu lócus de produção e reprodução social. Pode, também, confluir para o desenvolvimento de um turismo encabeçado pelos forasteiros, que têm maior poder econômico e de articulação, sendo eles a lucrar com a atividade, e mais uma vez, a comunidade local poderá ser excluída. Isso vai depender da forma como a atividade será desenvolvida e das políticas públicas para o setor.

Para finalizar a análise dos fenomenos retro- interacionais, os instrumentos de gestão das UCs do mosaico foram analisados, verificando-se sua aplicabilidade. Estão previstos no SNUC alguns instrumentos de gestão que garantem que as UCs sejam geridas e manejadas adequadamente, dos quais tem-se: o ZEE (zoneamento ecológico Economico), o plano de Manejo, o Plano de Gestão e os conselhos gestores.

O ZEE da APA Cachoeira das Andorinhas foi entregue ao Secretário de Estado do Meio Ambiente, em 2006, sendo concebido como um instrumento preliminar de planejamento, que subsidiaria a gestão dos recursos naturais e humanos presentes na área. (Jornal do Projeto Manuelzão, 2006). Vale ressaltar que foi realizado um extenso trabalho de levantamento de dados, pesquisas de campo e contatos com a comunidade, sendo o ZEE uma importante fonte de dados sobre a APA. Destaca-se, ainda, o grande envolvimento da comunidade no processo. A importância desse estudo é realmente inegável, principalmente por dividir a APA em zonas que permitem o uso sustentável de parte de seus recursos, visando garantir uma fonte de renda para a comunidade, a melhoria de sua qualidade de vida, aliada à conservação dos recursos naturais.

O problema é que, desde a sua entrega oficial, nada mais foi feito. As áreas e zonas estabelecidas deveriam servir de base para incentivar certas atividades, proibir outras, deferir ou indeferir processos de licença para desmate, dentre outras funções. Na prática, muito dinheiro público foi investido sem modificar a dinâmica e a realidade da comunidade. As demandas apresentadas nas oficinas ainda são queixas constantes e o manejo florestal continua sendo a principal reivindicação, gerando conflitos entre a comunidade e os órgãos gestores das UCs.

Além disso, a descontinuidade das ações e a demora no atendimento das demandas da comunidade, acabam gerando frustrações em relação às expectativas criadas pela comunidade, como pode ser percebido pelo discurso abaixo, de um pesquisador que trabalhou no levantamento de dados do ZEE:

Teve as oficinas, o zoneamento e tudo, a comunidade participou intensamente. Mas isso foi em maio de 2006. E de lá para cá? Como que a comunidade fica? As pessoas acreditaram, confiaram. E quanto aos resultados daquilo? Ah, tem que criar o conselho... O conselho foi criado recentemente, mas isso para a comunidade não tem muita diferença não. Mas pensa só o quê que foi para a comunidade? Daí vem o descrédito, fica difícil de arrumar parceria com a comunidade. As pessoas ficam com aquela expectativa e isso vai morrendo. Daí, daqui a pouco, vem uma autuação, a pessoa desanima. (Pesquisador, entrevista realizada em 21/07/08).

Além de colocar em prática o ZEE é necessário que seja elaborado o Plano de Gestão da APA. Esta UC foi criada há quase vinte anos e, ainda hoje, não possui tal documento, fato que acaba restringindo as possibilidades de uso da terra e a capacidade de produção e reprodução social de sua população, sem, no entanto, trazer benefícios que garantam a sua permanência na região, de forma digna e justa.

Além do Plano de Gestão da APA, fazse necessário que as demais UCs também elaborem 
seus Planos de Manejo de forma a atingir os objetivos para o qual foram criadas. Vale destacar que tanto o Parque quanto a Floresta estão implantando infra-estrutura para recebimento de visitante e para possibilitar o trabalho da administração das UCs. Porém, estas obras estão sendo realizadas sem um estudo técnico que dê respaldo em relação à melhor localização, aos materiais utilizados, à arquitetura e à integração paisagística dos mesmos, informações que devem constar no Plano de Manejo, como previsto no SNUC.

Além disso, parece haver uma intencionalidade por parte da administração da Floresta do Uaimii em relação ao plano de manejo para que não haja manejo florestal dentro da UC e sim para que a Floresta seja um local de produção de técnicas e pesquisas em manejo florestal. Os depoimentos abaixo corroboram com essa afirmação:

Então, gente, o Plano de Manejo da Floresta não é para mostrar para a comunidade onde ela vai entrar e tirar e quanto tirar, não. Isso não pode acontecer em nenhuma unidade de conservação. A Floresta vai ter um Plano de Manejo para ver o que vai ser tirado, como vai ser o manejo da Floresta, como vai ser o uso sustentável dela. O Plano de Manejo vem para orientar a gerência e todos os funcionários de como cuidar da Floresta, de como proteger e também vai orientar como trabalhar o entorno da unidade de conservação. (Funcionário do IEF, reunião do DIPUC, 26/08/08).

O problema central da questão é que ainda existe pouca experiência do Estado em relação à gestão dessa categoria de UC, e uma unidade de uso sustentável parece ser gerida como de proteção integral, como colocado pelos entrevistados abaixo:

Essa questão de desenvolvimento sustentável ainda é um gargalo, entendeu? Como conciliar comunidade, conservação e manejo? Eu acho que o IEF ainda não pegou isso. Daí trata como se fosse unidade de proteção integral. (...) Porque você tem que criar alternativas, você não pode chegar lá, proibir e pronto acabou. E é isso que acontece, trata como se tudo fosse parque. Aí você cria uma resistência. (Representante de ONG, entrevista realizada em 16/09/08).

Por fim, vale destacar a importância de um outro instrumento de gestão que é o conselho gestor de UCs. O Conselho da APA, atualmente, está funcionando de forma conjunta com o conselho da Floresta e há uma grande expectativa de que ele, de fato, se efetive como lócus de explicitação de conflitos e de resolução dos problemas que dizem respeito à relação sociedade $X$ meio ambiente na APA Cachoeira das Andorinhas. O conselho da APA funcionou de forma muito incipiente e descontinuada, no passado.

Espera-se, agora, que ele se fortaleça e realmente demonstre a sua importância para a comunidade e para os órgãos gestores, funcionando como uma instância participativa e democrática. Isso dependerá da importância que os gestores darão a este fórum, bem como do reconhecimento do papel de cidadão por parte da comunidade e dos conselheiros, que devem assumir a função como algo realmente importante para o coletivo.

De acordo com o Secretário Municipal de Meio Ambiente de Ouro Preto, o Parque das Andorinhas ainda não tem um conselho, mas há a intenção de que o CODEMA-OP represente esse fórum de participação na gestão do Parque. Porém, seria mais interessante que o Conselho Conjunto da APA e da Floresta incluísse também o Parque, instituindo, assim, uma gestão de fato compartilhada do mosaico de UCs, como preconiza o SNUC. Com certeza isso esbarra em uma série de desafios, e o principal deles diz respeito ao nível de governo que cada unidade está vinculada e às dificuldades de diálogo entre o poder público municipal e o poder público estadual.

Percebe-se, então, que no mosaico de UCs da APA Cachoeira das Andorinhas os conselhos ainda têm atuação incipiente como instrumento de gestão, sendo necessário um extenso trabalho para que essa instância participativa exerça o seu papel, se afirme e seja reconhecida como lócus de participação da comunidade e de discussão de problemas e conflitos relativos ao planejamento e gestão dessas UCs.

Por fim, vale ressaltar que a 
Paradoxos e complexidade na gestão do mosaico de unidades de conservação da área de proteção ambiental cachoeira das andorinhas - ouro preto/mg. pp. $90-106$.

análise dos fenômenos retro-interacionais aqui apresentada possibilitou refletir sobre os paradoxos e as contradições da gestão do mosaico da APA, considerando-se as diversas variáveis que interferem nessa realidade e que cada um dos fenômenos analisados são fragmentos de uma realidade complexa, que não podem ser entendidos fora do seu contexto.

Deve-se destacar, ainda, que os paradoxos e as contradições identificados estão relacionados com uma problemática ainda mais complexa, que se refere à necessidade da sociedade moderna criar UCs para proteger a natureza da destruição causada pelo próprio homem; e a necessidade de sobrevivência das comunidades locais, que possuem estilos de vida de grande dependência em relação aos recursos naturais. Esse paradoxo permeia toda a análise aqui realizada e é o que faz com que se torne tão difícil implementar e gerir UCs de uso sustentável, que têm como filosofia a difícil tarefa de compatibilizar o desenvolvimento econômico com a proteção ambiental.

\section{CONCLUSÕES}

A APA Cachoeira das Andorinhas e as demais UCs desse mosaico foram criadas com o objetivo de proteger os recursos naturais e, ao mesmo tempo, melhorar as condições de vida das comunidades locais. Porém, após a pesquisa, foi possível perceber que a comunidade, ao contrário do previsto, é quem menos tem se beneficiado com as ações e aplicações de leis ambientais incidentes sobre a área. Um dos motivos que justifica tal afirmação é o crescente êxodo rural, acentuado após a criação da APA, juntamente com o aumento das restrições impostas pela Lei da Mata Atlântica.

Pelas atividades que estão sendo desenvolvidas na implantação das UCs desse mosaico, parece que, mais importante do que manter a qualidade de vida da comunidade e sua permanência em seu lócus de produção e reprodução social, é garantir a preservação do meio ambiente. Os processos ecológicos naturais devem ser defendidos, mas as demandas da comunidade não podem ser negligenciadas. Considerando-se que se tratam de áreas abrangidas por unidades de conservação de uso sustentável (exceto a área do Parque), parece haver um equívoco em relação à forma como elas estão sendo geridas, uma vez que, de acordo com o SNUC: "O objetivo básico das Unidades de Uso Sustentável é compatibilizar a conservação da natureza com o uso sustentável de parcela dos recursos naturais."

Ressalta-se o paradoxo existente em função das restrições impostas sobre a comunidade e a percepção de que processos degradadores do meio ambiente continuam ocorrendo. As leis ambientais restringem o uso de recursos naturais, a comunidade sente que está sendo cerceada no desenvolvimento de diversas atividades econômicas importantes para seu sustento, porém, os processos de degradação e o descumprimento das leis ambientais continuam a ocorrer. Portanto, parece que as restrições impostas pela legislação valem mais para a comunidade, que na realidade é quem menos degrada e que utiliza os recursos apenas para a própria sobrevivência.

Apesar de o processo de extração de lenha e de alteração do uso do solo terem diminuído, essas práticas ainda ocorrem em alguns locais. Porém, a comunidade não pode cortar um feixe de madeira para usar no fogão à lenha. Será que isso está certo? Será que os gestores dessas UCs não deveriam colocar em prática a flexibilização para o uso da lenha, permitida por lei? Será que os processos de licenciamento para corte de lenha e alteração do uso do solo não deveriam levar em consideração as características e dinâmicas próprias de cada comunidade? Na prática, o que se vê é a aplicação de uma lei cega, que não diferencia consumo próprio de uso comercial, e acaba incidindo sempre com maior pressão sobre o lado mais fraco, ou seja, a comunidade.

Ressalta-se, ainda, que tanto a implantação das UCs, como as restrições impostas pelas leis ambientais e pelas políticas de tombamento fazem valer muito mais a parte restritiva da lei, do que aquelas que trazem benefícios à comunidade, como programas e projetos educativos, de fornecimento de créditos, 
incentivos e/ou financiamentos.

Esta pesquisa permitiu concluir, também, que tanto a criação de UCs como a aplicação de leis ambientais na área foram responsáveis por instituir mudanças no modo de vida da comunidade. Tais mudanças referemse, principalmente, às formas de trabalho e de geração de renda. Atividades como a exploração dos recursos florestais para a venda e/ou produção de carvão, mineração, extração de pedras, agricultura e pecuária entraram em declínio em função da criação das UCs e das restrições das leis ambientais. Algumas dessas atividades continuam sendo desenvolvidas, mas em menor escala. Outras foram proibidas e, o que anteriormente era uma prática tradicional da população, passou a ser considerado crime ambiental. Esses fatores, além de levar muitos trabalhadores para a clandestinidade, contribuíram de forma determinante para o aumento do desemprego, diminuição das possibilidades de geração de renda e conseqüentemente, aumento do êxodo rural.

Pôde-se perceber, ainda, que as restrições em relação ao uso dos recursos estão modificando, também, as práticas de preparo dos alimentos, pois gradativamente o uso do fogão à lenha está sendo substituído pelo fogão à gás. Esse fato tem incidência, também, na fabricação de doces que, de acordo com o Inventário de Registro do seu Processo de Fabricação, deve ser feito no fogão à lenha, seguindo as tradições locais.

Diante desse quadro, cabe-nos fazer uma pergunta: será que no futuro a população local terá condições de viver dignamente nessa região? Ou essas pessoas terão que deixar suas terras para tentar a vida árdua dos grandes centros? Diante desse impasse, resta, também, a esperança de que a gestão desse mosaico de UCs consiga resolver esse paradoxo, implementando, de fato, uma política de conservação ambiental que leve em consideração as demandas da comunidade, como ressalta um representante de Associação Comunitária: "A gente houve falar que não pode tirar lenha aí, que não pode degradar, mas eles não podem tirar o direito das pessoas sobreviverem" (Representante de Associação Comunitária, entrevista realizada em 21/07/08). Ou ainda o depoimento desse Produtor Rural:

É aquela coisa... Nós temos que ver isso com muito carinho, o pessoal do IEF. Porque se não daqui a pouco quem vai entrar em extinção é o homem do campo. [...] é aquele negócio, tem que olhar isso direitinho porque o homem do campo tá encurralado. (Produtor Rural, reunião do DIPUC, 26/08/08).

Ressalta-se, porém, que os paradoxos e as contradições aqui analisados não são frutos de uma gestão ineficiente, fragmentada ou unidimensional do mosaico de UCs da APA Cachoeira das Andorinhas. Estão, também, relacionados à dificuldade de se implantar formas sustentáveis de desenvolvimento econômico, que considerem as demandas da comunidade, os processos ecológicos em curso, as possibilidades de desenvolvimento econômico, as características culturais das comunidades e a gestão integrada e participativa dos recursos naturais.

Assim, compreendendo este mosaico como um sistema complexo, os paradoxos, resultantes de sua gestão não requerem ações isoladas. Como argumenta Gondolo (1999) sistemas complexos requerem respostas complexas. É preciso, portanto, promover interferências mútuas e integradas, que visem uma modificação nas interações entre os elementos que conformam este sistema complexo.

Vale destacar que, apesar das críticas aqui apresentadas, considerando-se as dificuldades inerentes da própria categoria APA, principalmente no que diz respeito ao gerenciamento de propriedades privadas e à atuação de vários agentes com interesses diversos, a APA Cachoeira das Andorinhas, pode ser considerada uma das poucas APAs implementada, podendo, inclusive, servir de modelo para muitas outras.

Isso não significa que os problemas não existam, muito pelo contrário. Justamente por não haverem muitas referências positivas no gerenciamento de APAs é que os desafios são enormes. Isso faz com que seja de grande importância o fortalecimento de uma gestão integrada do mosaico, que se consolide como 
Paradoxos e complexidade na gestão do mosaico de unidades de conservação da área de proteção ambiental cachoeira das andorinhas - ouro preto/mg . pp. 90 - 106.

referência nacional de gestão conjunta. E isso só será possível por meio de um trabalho contínuo e integrado dos órgãos gestores, bem como do fortalecimento do conselho conjunto para conseguir enfrentar as crescentes pressões do desenvolvimento econômico.
Para tanto, é preciso enfrentar os desafios, superar os paradoxos e as contradições existentes, na perspectiva de construir uma gestão integrada desse sistema complexo, e isso se dará por meio da construção de um saber socioambiental complexo e multidimensional.

\section{Notas}

Estéreo é unidade de medida volumétrica para madeira bruta; (Decreto 44.844/2008). Um metro cúbico de madeira equivale à 1 estéreo.

\section{Bibliografia}

BRASIL. Lei $n^{\circ} 9.985$, de 18 de julho de 2000. Regulamenta o art. 225, parágrafo $1^{\circ}$, incisos I, II, III e VII, da Constituição Federal, institui o SNUC e dá outras providências. Brasília, 2000.

BRASIL. Decreto $n^{\circ} 4.340$, de 22 de agosto de 2002. Regulamenta artigos da Lei 9.985 , de 18 de julho de 2000, que dispõe sobre o Sistema Nacional de Unidades de Conservação - SNUC, e dá outras providências. Brasília, 2002.

BRASIL. Lei $n^{\circ} 11.428$, de 22 de dezembro de 2006. Dispõe sobre a utilização e proteção do Bioma Mata Atlântica, e dá outras providências. Brasília, 2006.

CAMARGOS, Regina. Reservas Naturais no Brasil: a transição dos conceitos. Dissertação de mestrado, IGC/UFMG, Belo Horizonte, 1999.

DELAMARE, Alcibíades. Villa-Rica. São Paulo: Cia Editora Nacional, 1935.

DIEGUES, Antonio Carlos. O mito moderno da natureza intocada. $3^{\circ}$ ed. São Paulo: Hucitec/ Núcleo de Apoio à Pesquisa sobre Populações Humanas e Áreas Úmidas Brasileiras/ USP, 2000.

GONDOLO; Graciela Cristina Fernandez. Desafios de um sistema complexo à gestão ambiental: bacia do Guarapiranga, região metropolitana de São Paulo. $1^{\circ}$ edição. São Paulo: Annablume/ FAPESP, 1999.

GONTIJO, B. M. A ilusão do ecoturismo na Serra do Cipó / MG: O caso de Lapinha. Tese de Doutorado. CDS/UnB, Brasília, 2003.

INSTITUTO ESTADUAL DE FLORESTAS /
UNIVERSIDADE FEDERAL DE VIÇOSA. Relatório do zoneamento ecológico econômico da Área de Proteção Ambiental Cachoeira das Andorinhas. Viçosa, 2006.

IEF/SAT. Reserva da biosfera da Serra do Espinhaço: proposta de criação - fase I. (Instituto Estadual de Florestas/Sociedade Amigos do Tabuleiro). Belo Horizonte, 2005.

IBAMA. Documento de consulta pública para a criação da Floresta Nacional do Uaimii. Brasília, 2002.

LEFF, E. Aventuras da epistemologia ambiental: da articulação das ciências ao diálogo de saberes. Trad. de Gloria Maria Vargas. Rio de Janeiro: Garamond, 2004.

MACHADO, Carlos Augusto Pessoa. Projeto de implantação de infra-estrutura turística em São Bartolomeu. Belo Horizonte: Escola de Arquitetura / UFMG, 2001.

MANUELZÃO. Tripuí e Uaimií ganham nova infraestrutura. Disponível em <www.manuelzão. ufmg.br>. Acesso em 13/12/2006.

MINAS GERAIS. Decreto $n^{\circ} 30.264$, de 16 de Outubro de 1989. Dispõe sobre a implantação de Área de Proteção Ambiental - APA, no município de Ouro Preto. Belo Horizonte, 1989.

MINAS GERAIS. Decreto $n^{\circ} 42.912$, de 26 de setembro de 2002. Altera o Decreto n030.264, de 16 de outubro de 1989, que dispõe sobre a implantação de Área de Proteção Ambiental - APA, no município de Ouro Preto - APA Cachoeira das Andorinhas, 2002. 
MINAS GERAIS. Decreto sem número, de 21 de outubro de 2003. Cria a Floresta Estadual do Uaimii, no Estado de Minas Gerais. 2003.

MINAS GERAIS. Decreto 44.844, de 26 de junho de 2008. Estabelece normas para licenciamento ambiental e autorização ambiental de funcionamento, tipifica e classifica infrações às normas de proteção ao meio ambiente e aos recursos hídricos e estabelece procedimentos administrativos de fiscalização e aplicação das penalidades. 2008.

MORIN, E. Introdução ao pensamento complexo. Trad. Dulce Matos. Paris: Instituto Piaget/ESF éditeur. (Coleção Epistemologia e Sociedade), 1990.

OURO PRETO - Lei $n^{\circ} 305$, de 1968. Cria o Parque Municipal Cachoeira das Andorinhas. Ouro Preto, 1968.

OURO PRETO. Lei $n^{\circ}$ 69, de 21 de julho de 2005. Altera a Lei 305/68 que cria o Parque Municipal da Cachoeira das Andorinhas do Município de Ouro Preto, acrescenta dispositivos e dá outras providências. Ouro Preto, 2005.

PREFEITURA MUNICIPAL DE OURO PRETO. Inventário da Tradicional Produção de Doces Artesanais de São Bartolomeu - Secretaria
Municipal de Cultura e Turismo. Diretoria de Promoção Cultural, Ouro Preto, 2008.

PREFEITURA MUNICIPAL DE OURO PRETO. Dossiê de Tombamento do Conjunto Urbano de São Bartolomeu. Secretária Municipal de Patrimônio e Desenvolvimento Urbano. Ouro Preto, março de 2007.

PREFEITURA MUNICIPAL DE OURO PRETO. Diagnóstico Fundiário do Parque Natural Municipal da Cachoeira das Andorinhas. Almeida Avaliações e Perícias. Ouro Preto, Março de 2006.

TORRES, Rodrigo Ramos. Distrito de São Bartolomeu/OP: um estudo sobre o potencial turístico de seu patrimônio cultural e natural. Relatório final do Projeto O cotidiano e o espetáculo: paisagem, memória e turismo nos municípios de Ouro Preto e Mariana. Belo Horizonte, 1999.

UNIVERSIDADE FEDERAL DE OURO PRETO. Diagnóstico ambiental da área de preservação da Serra da Brígida, Município de Ouro Preto/MG. Ouro Preto, 2001.

UNIVERSIDADE FEDERAL DE VIÇOSA / INSTITUTO ESTADUAL DE FLORESTAS. Zoneamento ecológico da Área de Proteção Ambiental Estadual Cachoeira das Andorinhas. Ouro Preto, Minas Gerais: relatório do meio biótico. Viçosa, 2005 (relatório preliminar). 